\title{
Climate response of rainfed versus irrigated farms: the bias of farm heterogeneity in irrigation
}

\author{
Janka Vanschoenwinkel ${ }^{1}$ (D) $\cdot$ Steven Van Passel $^{2}$
}

Received: 24 September 2017 / Accepted: 5 January 2018 / Published online: 16 January 2018

(C) The Author(s) 2018. This article is an open access publication

\begin{abstract}
Researchers who do not take into account farm heterogeneity in implementing specific climate change adaptation options might significantly bias their findings. To prove this point, this paper focusses on irrigation as an adaptation option to climate change and highlights the fact that there is no such thing as "irrigation." Instead, different farms consider water management options across a spectrum that ranges from purely rainfed farms to purely irrigated farms with in between the extreme practices such as supplemental irrigation, water conservation practices, and different irrigation techniques. Accounting for such differences is necessary, yet difficult due to a lack of farm-specific data on water management and irrigation. This paper uses unique Farm Accountancy Data Network data of Western European farmers on the proportion of farmland that each farm irrigates. Unlike previous work, this allows taking into account some within-irrigation heterogeneity instead of simply categorizing farms as being "irrigated." We estimate and compare climate response models based on the Ricardian cross-sectional method for a large range of irrigation categories. The results give insights into how the farm irrigation climate response can be significantly different depending on how irrigation is defined. This proves that ignoring within-adaptation differences when comparing non-adaptation with adaptation (in this case, rainfed versus irrigated agriculture) might lead to biased conclusions with regard to effectiveness of adaptation strategies. We therefore argue that it might be more relevant to understand at which point and under which circumstances irrigated agriculture is more or less beneficial than rainfed agriculture.
\end{abstract}

Electronic supplementary material The online version of this article (https://doi.org/10.1007/s10584-0182141-2) contains supplementary material, which is available to authorized users.

Janka Vanschoenwinkel

janka.vanschoenwinkel@gmail.com

Steven Van Passel

steven.vanpassel@uantwerp.be

1 Doctoral School of Behavioral Sciences \& Humanities, Research Group of Environmental Economics, Hasselt University, Agoralaan Building D, Diepenbeek, Belgium

2 Department Engineering Management, University of Antwerp, Prinsstraat 13, Antwerp, Belgium 


\section{Introduction}

Given the fact that irrigated agriculture is claimed to be less sensitive to changes in climate than rainfed agriculture (Kurukulasuriya et al. 2006), it should be an eye-opening fact to see that within irrigated agriculture, marginal increases in temperature and precipitation have significantly different impacts all over the world. It is true that to a certain extent, this is explained by different levels of technological capacity, regional differences, and crop choice (Vanschoenwinkel et al. 2016). However, it should also be questioned how much researchers unintentionally contribute to these differing regional conclusions by bluntly categorizing farmers in "rainfed" versus "irrigated" agriculture and comparing them as such. Nowadays, farmers consider water management options across a spectrum that ranges from purely rainfed farms to purely irrigated farms. In between the extremes, there are among other farmers that use supplemental irrigation on only part of their field, farmers that apply conservation practices to store water in the soil, farmers that add more surface- or groundwater to their fields, or farmers that irrigate on a very frequent basis (Molden 2007). This implies that two farmers, who "irrigate," can be significantly different from each other with regard to irrigation efficiency and effectiveness. This might explain differences in their climate responsiveness.

This paper therefore examines how farm categorization in rainfed versus irrigated farms influences research findings and conclusions. As such, we challenge the status quo by acknowledging that there is no such thing as "irrigation." The results of this paper have implications for numerous adaptation studies as they prove that heterogeneity in implementing adaptation options significantly influences results and therefore might be misleading.

\section{State of the art}

Agriculture is said to be "arguably the sector most affected by climate change" (p.1.) (Rosenzweig et al. 2014). Its production activity depends directly on climate inputs. However, agriculture is also partly a man-made system. This means that a response of a farm to climate is not a simple biophysical response. Instead, it can be "manipulated" to become a more profitable or less climate sensitive response (Helms et al. 1996; Reilly 1999). For instance, during periods of droughts or in water scarce regions, agriculture often relies on irrigation for its water requirements (Finger et al. 2011). Irrigated farms are less sensitive to climate change since irrigation has a moderating effect (Kurukulasuriya et al. 2006). It reduces dependency on and uncertainty of rainfall patterns and decreases interannual variability of production (Tubiello 2005).

It therefore seems that under unfavorable climate circumstances, irrigated agriculture is less sensitive than rainfed agriculture. However, looking at cross-sectional studies that compared irrigated versus rainfed agriculture, it appears to be hard to draw a line between the conclusions of different studies. Indeed, in Europe and China, on average irrigated agriculture appears to be less sensitive than rainfed agriculture (Van Passel et al. 2017; Wang et al. 2009). Yet, in Mexico, the marginal effect of temperature (MEt) and the marginal effect of precipitation (MEp) are more optimistic for rainfed agriculture than for irrigated agriculture (Mendelsohn et al. 2009). In Africa, irrigated farms seem to benefit from marginal increases in temperature, while they suffer from marginal increases in precipitation (Seo and Mendelsohn 2008c). Kurukulasuriya et al. (2006) show less supportive evidence of this negative MEp for irrigated 
farms. Finally, in Southern-America, the impacts of marginal increases in temperature and precipitation are the opposite of the impacts in Africa (Seo and Mendelsohn 2008a).

Clearly, even though under the same conditions, irrigated agriculture is assumed to be less sensitive to changes in climate than rainfed agriculture (Kurukulasuriya et al. 2006), it seems that there are significant differences between different study findings. Some of these inconsistent and contradicting findings are likely explained by differences in technology, knowledge, experience, and other factors inside and outside the farm (Reidsma et al. 2010). Yet, we believe that a large proportion of these differences is also explained due to the fact that it is rarely specified "what" irrigated agriculture entails. Two farmers who irrigate might be completely different with regard to their frequency or intensity of irrigation. They might use different irrigation techniques or extract the irrigation water from different resources which might influence the quality. Some farmers irrigate all their fields, while others only apply irrigation to part of their fields. As such, farmers can be assigned to a continuum of categories in between the extremes of purely rainfed agriculture to purely irrigated agriculture. Farmers in one of these categories (even though all categories are one form of irrigation) might respond differently to changes in climate than farmers in another irrigation category. It is therefore important to examine whether it is necessary to distinguish between different farm irrigation practices when comparing rainfed and irrigated agriculture.

To objectively compare different types of irrigated farms, one should have data on the quality, intensity, and frequency of irrigation, and the resulting investment and operational costs. In addition, it is important to know where the irrigation water comes from (e.g., surfaceor groundwater) and whether this water resource is renewable. There are also significant differences in irrigation technologies with regard to efficiency and effectiveness. Ideally, all these data should be available on a within-seasonal basis because irrigation requirements, costs, and applicability highly vary from season to season. All these data can influence a farmer's decision to irrigate and the resulting profitability of his decision.

\section{Data}

Unfortunately, data on specific farm irrigation characteristics only rarely exist on a detailed, farm scale level. Data that can be found through for instance Eurostat and FAO (2017) are mostly on an aggregated (e.g., country) scale and do not give sufficient information on farm differences in irrigation application, requirements, water usage, and related costs.

The data that we use are FADN (Farm Accountancy Data Network) data. FADN provides farm-specific measures of approximately 80,000 farm holdings in the European Union, which represent nearly 14 million farms with a total utilized agricultural area of about 216 million hectares. Their irrigation data register for each farm "the area of crops which have actually been irrigated at least once during the year" (p17) (European Commission 2014). Irrigation data on such a large scale are unique and give a more detailed picture of irrigation on farm level than most other datasets do. With these data, we can distinguish farmers based on their long-term irrigation investments regarding the percentage of UAA (utilized agricultural area) that they can irrigate. In a lot of cases, this is a fixed investment which puts a limit on the percentage of area that can be irrigated (for instance, the length of hoses and pipes, or the radius the sprinkler installation can reach). These data are therefore highly suited to examine the influence of climatic conditions on the farm long-term irrigation investments. Note however that these data are less suited to measure short-term farm-specific irrigation 
management strategies in response to weather conditions (such as the frequency of usage, and the amount and the quality of water used in the irrigation installations). This is outside the scope of this paper as we only research whether it is necessary to distinguish farm irrigation heterogeneity in response to climatic changes.

These farm-level irrigation data will be used to prepare different irrigation subsamples (see Section 3) to estimate different climate response functions. For the climate response functions themselves, we use the cross-sectional Ricardian method of Mendelsohn et al. (1994) and therefore use the same variables as previously peer-reviewed work did. That is, we link farm land values to specific socio-economic, geographic, climatic, biological, and farm influences. These variables are described and summarized in the Electronic Supplemental Material in Table S1 on the journal's website (see also Van Passel et al. (2017) and Vanschoenwinkel et al. (2016)). Farm land values are used because they are assumed to be proxies for the net present value of farm revenues and therefore more robust and stable than yearly revenues. In addition, the FADN data are collected uniformly and consistently over Europe which is important to correctly compare different regions. To describe climate, temperature and precipitation variables are used. These climate data are averaged into four seasons because there is a high correlation in climate data from month to month. Linear and quadric terms are introduced for both temperature and precipitation, since earlier field studies proved the non-linear nature of the net revenue function (Mendelsohn and Dinar 2003; Mendelsohn et al. 1994).

Apart from the farm-specific variables, all variables are on a NUTS3 geographical scale as for privacy reasons; it is not possible to link the farm holdings to unique locational coordinates. With regard to the sample of farmers taken, we dropped out all mixed and livestock farms to obtain better estimations with regard to irrigation. Finally, it should be noted that for this study, looking at the data of 1 year is enough because we only examine the farm response to climatic conditions. Using data of 2007, 2008..., or 2012 therefore should not change the results if data are sampled in the same way. However, we do show the findings of the period before 2008 (namely 2007) and after 2008 (namely 2012) because, as will be discussed in Section 5, starting from 2008, there were changes in the way farms are sampled.

\section{Method}

The method consists of three parts: (1) determining how the sample will be divided in rainfed versus irrigated farms depending on the percentage of UAA a farmer irrigates, (2) determining the climate response function per sample, and (3) deriving the marginal effects of temperature and precipitation per function. These three steps are repeated 1000 times so that different climate responses of different categorizations can be compared with one another. We now explain these three steps in more detail before showing the results.

The climate response itself is estimated by means of the cross-sectional Ricardian method as presented by Mendelsohn et al. (1994). The method uses data on farm land values, assuming that these are proxies for the net present value of farm revenues. Each farmer is assumed to maximize his profits (and thus his land value) by optimizing endogenous variables such as inputs, crop choices, and other management decisions. As such, such variables cannot explain changes in land value or revenues and only exogenous variables outside the control of the farmer are taken into account. The cross-sectional data used by the method allow comparing regions with different climatic, geographic, biophysical, and socio-economic characteristics to understand their influences on the farm climate response. For the purpose of this paper, we run 
the model with an ordinary least squares regression, but we split the full sample of farmers in an irrigated and a rainfed sample to determine the climate response function for each of these samples separately. This is also done by Kurukulasuriya et al. (2006), Mendelsohn and Dinar (2003), Schlenker et al. (2006), Seo and Mendelsohn (2008b), and Van Passel et al. (2017) who estimated separate response functions for rainfed and irrigated crops.

This irrigated and rainfed climate response is estimated 1000 times, for 1000 different farm categorizations in rainfed versus irrigated crops. The farm categorization in rainfed versus irrigated crops is done based on the percentage of UAA farmers irrigate. We call this percentage the irrigation threshold. If a farm irrigates at least $\mathrm{x} \%$ of its UAA, it is categorized as an irrigated farm. We allow to change this threshold $\mathrm{x}$ from 0.1 to $100 \%$ with steps of 0.1 throughout the analysis. As such, we make a different irrigation and rainfed categories for each irrigation threshold. In total, we use 1000 irrigation thresholds and as such, we determine 1000 rainfed and irrigation climate responses that can be compared with one another. This will help us to better understand whether a farmer that irrigates for instance only $1 \%$ of his UAA should be categorized as a true irrigated farm or not.

For each of these subsamples, based on one specific irrigation threshold, we compare the irrigated and rainfed agricultural climate response with regard to their annual marginal effect of temperature (MEt) and their annual marginal effect of precipitation (MEp) by checking whether they were significantly different from each other (Weighted Welch's $t$ test) and by comparing their absolute values. The marginal effects are necessary to determine because we both use linear and quadratic climate terms per season in the climate response functions (see Vanschoenwinkel et al. (2016)). Calculating the marginal effects per season is done as follows (determined separately for precipitation $(\mathrm{p})$ and temperature $(\mathrm{t})$ for season $\mathrm{i}\left(\mathrm{ME}_{\mathrm{i}}\right)$ ):

$$
\mathrm{ME}_{i}=\frac{\partial V}{\partial C_{i}}=\beta_{1, i}+2 \beta_{2, i} C_{i}
$$

The annual average marginal effect (MEt and MEp) is derived from the previous by taking the sum of the average seasonal marginal effects. The marginal effects can be interpreted as the percentage change in 1 ha land value associated with an increase of $1{ }^{\circ} \mathrm{C}$ in temperature for MEt or an increase of $1 \mathrm{~cm}$ in precipitation for MEp. Note that each marginal effect goes along with only one irrigation threshold as it is determined for each climate response function separately. Each marginal effect on each of the graphs is determined by a unique climate response function per irrigation threshold. The entire three-step procedure is repeated per year (in this case, 2007 and 2012) and per additional subsampling (small versus large farms).

These results are visualized in the graphs in the next section. The marginal effects of irrigation are presented by a blue line and the marginal effects of rainfed agriculture by a green line. The significance of the $t$ test is visualized by means of a red background. If there is no significant difference between rainfed and irrigated agriculture, these points will have a red background. However, with regard to the significance of the Welch's $t$ test, it should be noted that we only executed the $t$ test for discrete points ranging from $0.1-100 \%$. That means that there might still be points in between that we did not test for and that might yet be insignificantly different from each other. This can for instance be seen in Fig. $2 \mathrm{f}$ where the irrigated line suddenly drops below the rainfed line. In the point where the two lines intersect, there is obviously no significant difference between rainfed and irrigated agriculture. Yet, no red background is visible because the intersection must be somewhere between 95.2 and $95.3 \%$. We only tested for 95.2 and $95.3 \%$. Not for the values in between. 
Furthermore, we also indicate with a bar chart included in each graph, the size of the sample of irrigated farms. This is because, the higher the threshold, the lower the sample of irrigated farms that remains. To keep track of this evolution, the bar chart in the graph indicates how many farmers remain and at what percentage they irrigate. In case the categorization of farmers in irrigated or rainfed farmers does not matter, the blue line should be horizontal, meaning that each irrigation threshold results in a similar marginal effect or climate response.

\section{Results}

We determined for 1000 different categorizations of irrigation (that is 1000 irrigation thresholds), a climate response function for rainfed and irrigated agriculture. This implies that we have a total of 2000 regressions per analysis (1000 irrigated and 1000 rainfed climate responses) that have to be compared with one another. As this would be very cumbersome, we focus our analysis on the visualization of the marginal effects of climate of all these regressions. These can be found in the graphs below. In the Electronic Supplemental Material provided by the journal in Table S2, an example of the paper's linear regressions of the $50 \%$ threshold can be consulted for 2007 and 2012.

Figure 1 shows the marginal effects of temperature for 2007 and 2012, distinguishing the results of the entire sample compared to samples of large and small farms. Looking at the full sample in 2007 (Fig. 1a), there is clearly a positive relationship between the MEt and the percentage of UAA that a farmer irrigates. That is, farmers who irrigate a higher percentage of their UAA have a more positive MEt than rainfed farmers. Clearly, when no distinction is made between farmers that irrigate at least $73.1 \%$ of their UAA and farmers that irrigate a smaller part of their UAA, the analysis shows that the MEts of rainfed agriculture are more beneficial than the MEts of irrigated agriculture. The decision of the researcher to categorize farmers in one category or another therefore influences the final conclusion with regard to the effect of a marginal increase in temperature on irrigated versus rainfed agriculture.

Farm categorization is less of an issue when using data of 2012 (Fig. 1b). The MEts of 2012 are different from those in 2007 with regard to the fact that irrigated agriculture on average responds more beneficial than rainfed agriculture to marginal increases in temperature. No threshold with regard to the percentage of UAA irrigated must be exceeded, although there are points on the graph where the differences between rainfed and irrigated agriculture are not significant or where the MEts of irrigated agriculture sometimes become less beneficial than those of rainfed agriculture (in between the threshold of 40.7-83.4\%).

These results, however, slightly change if other farm differences are also taken into account. Farmers are very heterogeneous and different farm types (defined by characteristics such as farm size and crop choice) might respond differently to climate change and irrigation practices. It is therefore important to understand farm differences. In this paper, we compare small and large farms with each other and it can be seen that this explains the differences between 2007 and 2012. Looking at $1 \mathrm{c}$ and $1 \mathrm{~d}$, it can be seen that large farms in general have lower MEts when opting for irrigation, while small farms (1e and 1f) have more beneficial MEts in case they irrigate. Only in 2007, small farms first have to irrigate a minimum percentage of their UAA before the MEt of irrigation becomes more beneficial than the MEt of rainfed agriculture. This threshold to be exceeded before the MEts of small irrigated farms become more beneficial than those of rainfed agriculture needs to be smaller than when compared to the results of the full sample $(\sim 40.0 \%$ instead of $\sim 73.1 \%)$. As such, there are differences between 
a All farms sample MEt 2007

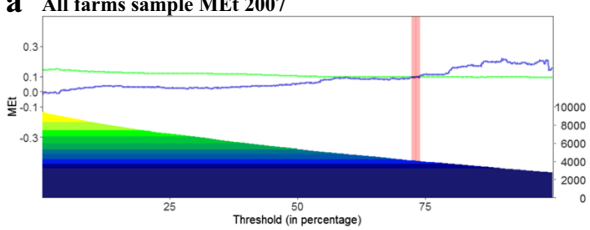

C Large farms sample MEt 2007

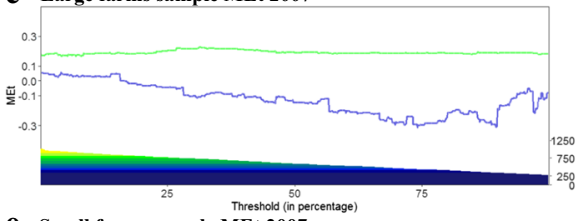

e Small farms sample MEt 2007

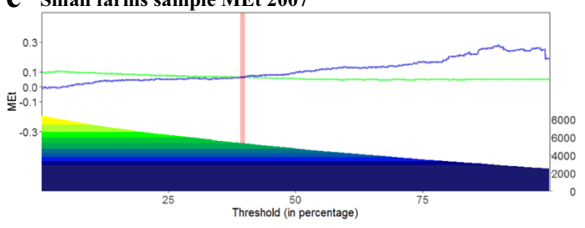

Number of irrigated farms

0-10\% irrigation $\quad 20-30 \%$ irrigation $\square$ - $\quad$ - $-50 \%$ irrigation $\square$ 60-70\% irrigation

10-20\% irrigation $\quad 30-40 \%$ irrigation $\square 50-60 \%$ irrigation b All farms sample MEt 2012

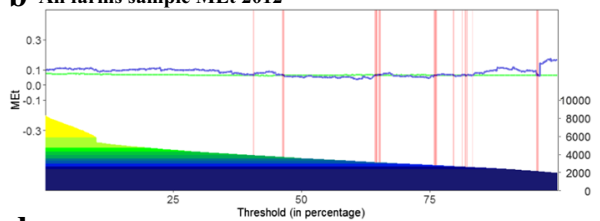

d Large farms sample MEt 2012

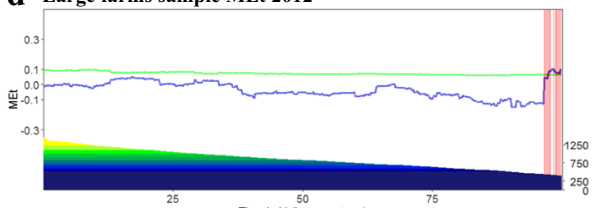

f Small farms sample MEt 2012

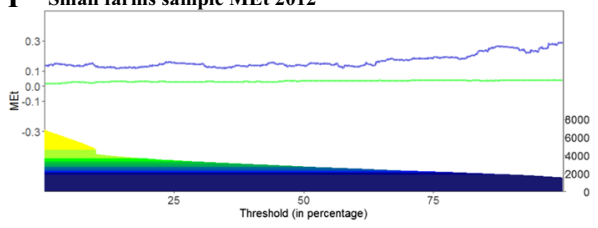

Significantly different at $1 \% \quad M E t$

No Yes $\quad$ imrigation - Rainfed

Fig. 1 Marginal effects of temperature (percentage change in 1 ha land value associated with an increase of $1{ }^{\circ} \mathrm{C}$ in temperature)

2007 and 2012 with regard to the proportion of large and small farms that influence the conclusion when looking at the results of the full sample.

With regard to the MEp, comparison between rainfed and irrigated farms is more straightforward. In both 2007 and 2012, independent of the percentage UAA irrigated, irrigated agriculture benefits more from decreases in precipitation than rainfed agriculture. Furthermore, the relationship between MEp and the percentage of UAA irrigated is negative, indicating that farms that irrigate a higher percentage of UAA are less vulnerable to decreases in precipitation. This negative relationship is mostly visible for large farms that irrigate as they use irrigation in particular to avoid the negative impacts of decreases in precipitation (Fig. 2c, d). Small irrigated farmers (Fig. 2e, f) benefit from additional precipitation or respond more neutral.

\section{Discussion}

The results prove our point of criticism; differences between long-term farm irrigation practices might influence the researcher's conclusion of whether rainfed or irrigated agriculture is more or less responsive to changes in climate. Farms that irrigate larger proportions of their UAA respond significantly different than farms that irrigate only occasionally. Researchers should therefore clearly define irrigated agriculture and not assume that all irrigated farms are the same.

Given the differences between farmers and their different irrigation strategies and customs, it is however not straightforward to say which threshold a researcher should take to analyze rainfed versus irrigated farmers. In addition, regarding the sampling of the data in small versus large farmers, it should be noted that comparison between large and small farmers in Europa might be hard due to the fact that large farms in Europe are located mostly in North-Western regions where more rainfed 

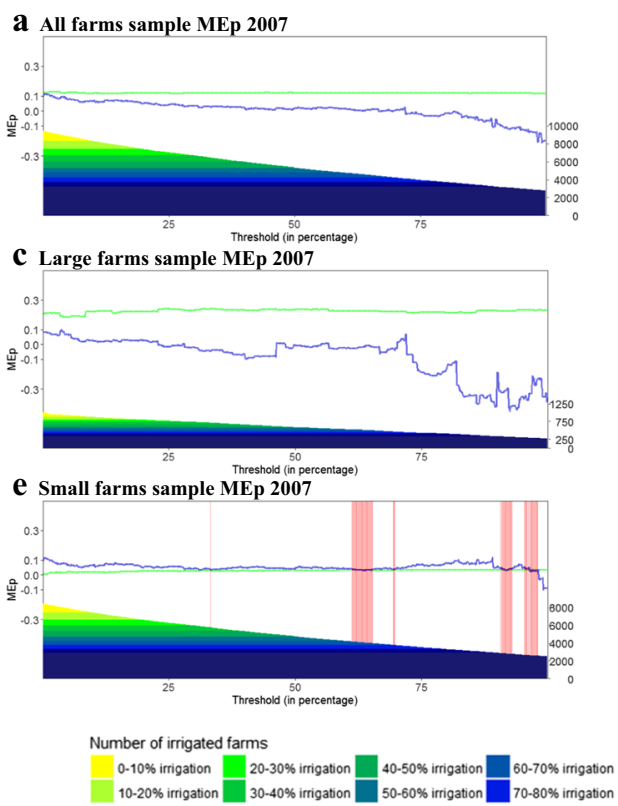

b All farms sample MEp 2012

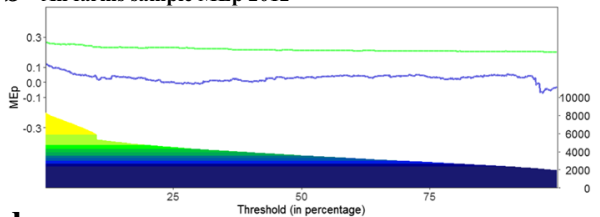

d Large farms sample MEp 2012

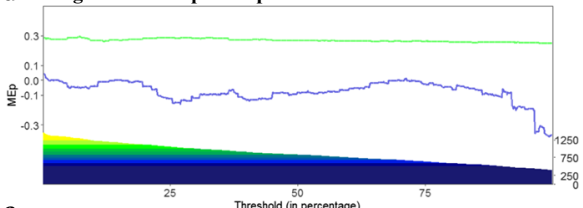

f Small farms sample MEp 2012

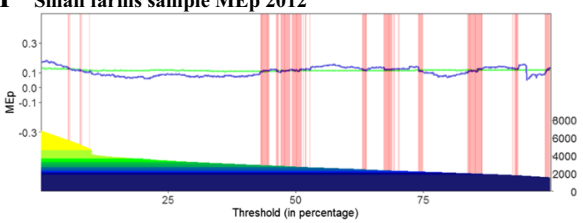

Significantly different at $1 \% \quad$ MEp

80-90\% irrigation No Yes - Irrigation - Rainted

Fig. 2 Marginal effects of precipitation (percentage change in 1 ha land value associated with an increase of $1 \mathrm{~cm}$ in precipitation for MEp)

agriculture is present. The results of large farmers should therefore not simply be generalized to all European farmers. Furthermore, Southern regions mostly have small farmers, and these farmers seem to prefer increases in precipitation (2007) or do not face serious consequences when precipitation increases (2012). This might indicate that they have less constant access to water resources and need additional precipitation to maintain their water reserves.

Further research is therefore needed to better understand how differences in irrigation influence farm climate responses. In this respect, it is important to understand that there is a difference between long-term responses to climate and short-term responses to weather. This study only measures the impact of climate change on the farm and not the impact of weather itself. To study the impact of weather changes, researchers should look more at short-term irrigation responses such as the intensity and frequency of irrigation, and the type of water used.

However, in case research further examines short-term irrigation management variables, it is important to understand that such variables increase endogeneity issues. This is due to the fact that short-term farm management is much more flexible and in control of the farmer than long-term irrigation investments. In this regard, it is important to improve methods in order to take into account such endogeneity issues. For the method and data used in this study, it is therefore more robust and correct to apply climatic data. In addition, the sample size of our data is large, minimizing possible biases. However, in case more flexible management variables are examined, endogeneity issues have to be accounted for. As such, even though frequently used (see Kurukulasuriya et al. (2006), Mendelsohn and Dinar (2003), Schlenker et al. (2006), Seo and Mendelsohn (2008b), and Van Passel et al. (2017)), it should be noted that the methodology of subsampling irrigated and rainfed farms is less accurate. This is a frequently cited problem which requires more research attention (see for instance Kurukulasuriya et al. (2011) and Chatzopoulos and Lippert (2016)). 
Thirdly, before it is possible to account for farm irrigation management heterogeneity, more farm irrigation data are needed. Given the fact that more institutions and researchers are aiming to collect more irrigation data, a peculiar finding of how sample characteristics can further influence differences between irrigated and rainfed farms of this paper should be highlighted regarding the FADN. With regard to the MEts, the climate responses of 2007 and 2012 differ significantly from another. However, given the fact that we use climatic control variables, it is unlikely that in such a short period of time, a region's climate response would change this drastically. Instead, these differences are caused by changes in the data sampling of large and small farmers in Italy between these years. Before 2007, the full Italian FADN sample contained about 17,000 farms. After 2007, only about 12,000 farms remained (Cisilino et al. 2011). This is possible because the data collection of the FADN occurs at country level and member states have their own selection plans (FADN 2016). Starting from the 2008 accounting year, the Italian survey system introduced a new software with related changes in data collection (Bodini and Marongiu 2009). One of the sampling differences in the Italian sample appears to be the exclusion of very large farm holdings. This has two implications for our analysis: (1) we weight based on farm size as measured by UAA and (2) most Italian irrigated farms are large and are as a result, dropped from the sample. The latter means that there is a decrease of more than $40 \%$ in Italian irrigated farms in our sample (from 4588 irrigated and 3019 rainfed farms in 2007, to 2652 irrigated and 2370 rainfed farms in 2012). Given the fact that most irrigated farms in Europe are situated in Italy, this is a very important change for our analysis. We tested the years 2008, 2009, 2010, and 2011 and concluded that our results of these 4 years are (as expected) similar to the results of 2012. Results only differ between the period before and the period starting from 2008 due to the sampling differences.

\section{Conclusion}

The climate response of irrigated versus rainfed agriculture highly differs depending on longterm farm irrigation decisions. As such, conclusions with regard to differences between the benefits of rainfed versus irrigated agriculture can highly differ depending on how irrigation is defined. Researchers should be aware of this and not blunty generalize their research conclusions to all irrigated farm types. There are certainly irrigation strategies that are more effective and efficient than others.

Research therefore needs to use more farm-specific irrigation and water management data. Given the fact that these data are not always available, it might also be relevant to understand better at which point and under which circumstances irrigated agriculture is more or less beneficial than rainfed agriculture. Finally, the criticism brought up by this paper should be taken further to other adaptation practices to understand how farm heterogeneity in implementing one adaptation option influences research findings. This should also be coupled to the adaptation decision process of the farm itself to tackle endogeneity issues.

Acknowledgements The authors would kindly want to express their gratitude towards DG AGRI for access to the Farm Accountancy Data Network (FADN).

Funding information This paper was supported by the Horizon 2020 project SUFISA (Grant Agreement No. 635577). 
Open Access This article is distributed under the terms of the Creative Commons Attribution 4.0 International License (http://creativecommons.org/licenses/by/4.0/), which permits unrestricted use, distribution, and reproduction in any medium, provided you give appropriate credit to the original author(s) and the source, provide a link to the Creative Commons license, and indicate if changes were made.

\section{References}

Bodini A, Marongiu S (2009) Chapter 22: innovations in the Italian FADN/RICA survey system approach: the new software GAIA and its implications on the Italian agricultural accounting system. In: Boone K, Teeuwen $\mathrm{C}$ (Eds) Pacioli 17 innovation in the management and use of micro economic databases in agriculture

Chatzopoulos T, Lippert C (2016) Endogenous farm-type selection, endogenous irrigation, and spatial effects in Ricardian models of climate change. Eur Rev Agric Econ 43(2):217-235

Cisilino F, Cagliero R, Scardera A (2011) Evaluating rural development programmes using FADN data

European Commission (2014) COMMITTEE FOR THE FARM ACCOUNTANCY DATA NETWORK Farm Return Data Definitions Accounting year 2014. Brussels, Belgium

FADN (2016) Sample selection. Available from: http://ec.europa.eu/agriculture/rica/methodology2_en.cfm

FAO (2017) FAOSTAT. Available from: http://www.fao.org/faostat/en/\#data/RL

Finger R, Hediger W, Schmid S (2011) Irrigation as adaption strategy to climate change — a biophysical and economic appraisal for Swiss maize production. Clim Chang 105:509-528

Helms S, Mendelsohn R, Neumann J (1996) The impact of climate change on agriculture. Clim Chang 33(1):1-6

Kurukulasuriya P, Kala N, Mendelsohn R (2011) Adaptation and climate change impacts: a structural Ricardian model of irrigation and farm income in Africa. Climate Change Economics 2(02):149-174

Kurukulasuriya P, Mendelsohn R, Hassan R, Benhin J, Deressa T, Diop M, Eid HM, Fosu KY, Gbetibouo G, Jain S, Mahamadou A, Mano R, Kabubo-Mariara J, El-Marsafawy S, Molua E, Ouda S, Ouedraogo M, Séne I, Maddison D, Seo SN, Dinar A (2006) Will African agriculture survive climate change? World Bank Economic Rev 20(3):367-388

Mendelsohn R, Arellano-Gonzalez J, Christensen P (2009) A Ricardian analysis of Mexican farms. Environ Dev Econ 15:153-171

Mendelsohn R, Dinar A (2003) Climate, water, and agriculture. Land Econ 79(3):328-341

Mendelsohn R, Nordhaus WD, Shaw D (1994) The impact of global warming on agriculture: a Ricardian analysis. Am Econ Rev 84(4):753-771

Molden D (2007) Water for food, water for life: a comprehensive assessment of water management in agriculture, London: Earthscan, and Colombo: International Water Management Institute

Reidsma P, Ewert F, Lansink AO, Leemans R (2010) Adaptation to climate change and climate variability in European agriculture: the importance of farm level responses. Eur J Agron 32(1):91-102

Reilly JM (1999) Climate change and agriculture: the state of the scientific knowledge. Clim Chang 43(4):645-650

Rosenzweig C, Elliott J, Deryng D, Ruane AC, Müller C, Arneth A, Boote KJ, Folberth C, Glotter M, Khabarov N, Neumann K, Piontek F, Pugh TAM, Schmid E, Stehfest E, Yang H, Jones JW (2014) Assessing agricultural risks of climate change in the 21 st century in a global gridded crop model intercomparison. Proc Natl Acad Sci 111(9):3268-3273

Schlenker W, Hanemann WM, Fisher AC (2006) The impact of global warming on U.S. agriculture: an econometric analysis of optimal growing conditions. Rev Economics Statistics 88(1):113-125

Seo SN, Mendelsohn R (2008a) An analysis of crop choice: adapting to climate change in South American farms. Ecol Econ 67(1):109-116

Seo SN, Mendelsohn R (2008b) A Ricardian analysis of the impact of climate change on South American farms. Chilean J Agricultural Res 68(1):69-79

Seo SN, Mendelsohn RO (2008c) A structural Ricardian analysis of climate change impacts and adaptations in African agriculture. World Bank Policy Research Working Paper Series, Vol

Tubiello NN (2005) Climate variability and agriculture: perspectives on current and future challenges. Impact of climate change, variability and weather fluctuations on crops and their produce markets. B. Knight, Cambridge, p 47-66

Van Passel S, Massetti E, Mendelsohn R (2017) A Ricardian analysis of the impact of climate change on European agriculture. Environ Resour Econ 67(4):725-760

Vanschoenwinkel J, Mendelsohn R, Van Passel S (2016) Do Western and Eastern Europe have the same agricultural climate response? Taking adaptive capacity into account. Glob Environ Chang 41:74-87

Wang J, Mendelsohn R, Dinar A, Huang J, Rozelle S, Zhang L (2009) The impact of climate change on China's agriculture. Agric Econ 40:323-337 